\title{
Development and Characterization of Microsatellite Markers for Three Pollination Morphs of Cimicifuga simplex (Ranunculaceae)
}

\author{
Tsubasa Toji ${ }^{*}$, Yoshiaki Kameyama², Akira S. Hirao ${ }^{3}$, Takao Itino ${ }^{4}$ \\ ${ }^{1}$ Graduate School of Science and Technology, Shinshu University, Matsumoto, Japan \\ ${ }^{2}$ Faculty of Regional Environment Science, Tokyo University of Agriculture, Tokyo, Japan \\ ${ }^{3}$ Sugadaira Research Station, Mountain Science Center, University of Tsukuba, Tsukuba, Japan \\ ${ }^{4}$ Department of Biology and Institute of Mountain Science, Shinshu University, Matsumoto, Japan \\ Email: ${ }^{* 17 s s 504 j @ s h i n s h u-u . a c . j p ~}$
}

How to cite this paper: Toji, T., Kameyama, Y., Hirao, A.S. and Itino, T. (2018) Development and Characterization of Microsatellite Markers for Three Pollination Morphs of Cimicifuga simplex (Ranunculaceae). American Journal of Plant Sciences, 9, 599-605.

https://doi.org/10.4236/ajps.2018.94046

Received: January 25, 2018

Accepted: March 5, 2018

Published: March 8, 2018

Copyright $(0) 2018$ by authors and Scientific Research Publishing Inc. This work is licensed under the Creative Commons Attribution International License (CC BY 4.0).

http://creativecommons.org/licenses/by/4.0/

\begin{abstract}
Cimicifuga simplex Wormsk. (Ranunculaceae) is a perennial herb distributed in eastern and northeastern Asia for which at least three different pollination morphs have been reported. It is classified as endangered or near threatened in some Japanese regions, and its rhizome is commercially used as a crude drug. To examine genetic differentiation and gene flow among the three morphs, we developed eight microsatellite markers by using next-generation sequencing and estimated the genetic structure of $C$. simplex. We tested eight primer pairs on 93 individuals from six populations of C. simplex in Nagano, central Japan, and found that heterozygosity in morphs I and III was low compared to expected heterozygosity. Bayesian clustering performed with the STRUCTURE program clearly distinguished the three morphs of $C$. simplex, and only a little gene flow was detected among the morphs. These eight microsatellite markers are expected to be useful in conservation genetic studies of this species and for future conservation planning.
\end{abstract}

\section{Keywords}

Cimicifuga simplex, Genetic Structure, Microsatellite Marker, Next-Generation Sequencing, Pollination Morph

\section{Introduction}

Cimicifuga simplex Wormsk. (Ranunculaceae) is a perennial herb distributed in eastern and northeastern Asia [1] [2] that is classified as endangered or near threatened in three of the 47 Prefecture Red Data Book lists of Japan [3]. Its rhi- 
zome is commercially used as a crude drug [4]. Accordingly, for the conservation and sustainable pharmacological use of this species, it is important to evaluate its genetic diversity and genetic structure.

C. simplex comprises at least three different pollination morphs [5] (henceforth morphs I, II, and III). Morphs I and III are pollinated mainly by bumblebees, and morph II is pollinated mainly by butterflies [5]. The three morphs differ in their altitudinal distribution, habitats, flowering season, and nuclear internal transcribed spacer gene sequences [6], although the actual state of gene flow among the different morphs is unknown.

Therefore, we used next-generation sequencing to develop eight nuclear microsatellite markers for $C$. simplex and estimated its genetic structure for a preliminary assessment of genetic differentiation and gene flow among the three morphs.

\section{Materials and Methods}

\subsection{DNA Extraction and Library Construction}

Each sample was a fresh leaf collected from an individual $C$. simplex plant growing in Nagano Prefecture, Japan. Genomic DNA was extracted from the leaf with the DNeasy Plant Mini Kit (QIAGEN, Germantown, Maryland, USA), and the extracted DNA was used for library preparation. The library was constructed from morph II individual. A 5' and 3' adapter was ligated for random fragmentation DNA. The adapter-ligated fragments were then amplified by polymerase chain reaction (PCR) and gel purified. Each fragment was amplified into distinct clonal clusters by bridge amplification.

\subsection{DNA Sequencing and Microsatellite Isolation}

We performed DNA sequencing on a Miseq sequencer (Illumina, San Diego, CA) using approximately $10 \%$ of a plate. The filtered reads were assembled de novo into contigs by using Newbler software (Roche, Basel, Switzerland). The QDD version 3.1 [7] bioinformatics pipeline was used to identify contigs possessing microsatellite motifs as well as to design primer pairs. We searched for primers with the following specifications: melting temperature $\left(T_{\mathrm{m}}\right)$ of $57^{\circ} \mathrm{C}-$ $63^{\circ} \mathrm{C}$, PCR product between 100 and $300 \mathrm{bp}$ long, and primer length between 18 and 27 nucleotides. We identified 96 candidate primer pairs meeting these specifications and tested them using DNA samples from eight $C$. simplex individuals. For all tested microsatellite loci, the forward primers were synthesized with one of four different universal fluorescent sequences added, 5'-GCCTCCCTCGCGCCA-3', 5'-GCCTTGCCAGCCCGC-3', 5'-CAGGACCAGGCTACCGTG-3'， or 5'-CGGAGAGCCGAGAGGTG-3' [8], and a 5'-GTTTCTT-3' PIG-tail [9] was added to all reverse primers.

\subsection{Microsatellite Genotyping}

The PCR amplification was performed in a $6 \mu \mathrm{L}$ reaction volume containing 10 
ng template DNA, 3.0 $\mu \mathrm{L} 2 \times$ Type-it Multiplex PCR Master Mix (QIAGEN, Valencia, California, USA), $0.1 \mu \mathrm{M}$ forward primer, $0.2 \mu \mathrm{M}$ reverse primer, and 0.1 $\mu \mathrm{M}$ fluorescent labeled universal primer. In the multiplex PCR, the final concentration of each forward primer and fluorescent-labeled universal primer was 0.1 $\mu \mathrm{M}$, and the final concentration of each reverse primer was $0.2 \mu \mathrm{M}$. The PCR thermal profile was as follows: initial denaturation at $95^{\circ} \mathrm{C}$ for $5 \mathrm{~min}$; followed by 35 cycles of $95^{\circ} \mathrm{C}$ for $30 \mathrm{~s}, 60^{\circ} \mathrm{C}$ for $1.5 \mathrm{~min}$, and $72^{\circ} \mathrm{C}$ for $30 \mathrm{~s}$; and a final extension at $60^{\circ} \mathrm{C}$ for $30 \mathrm{~min}$. The PCR products were detected by using a ABI Prism 3130 Genetic Analyzer (Applied Biosystems, Waltham, Massachusetts, USA). Fragment lengths were calculated by using the GeneMapper version 4.0 program (Applied Biosystems).

\subsection{Genetic Analysis}

We used the eight primer pairs identified by the screening to analyze 93 individuals from six populations of $C$. simplex in Nagano Prefecture, central Japan (morph I, Norikura_1 36 $12^{\prime} 29^{\prime \prime} \mathrm{N} \quad 137^{\circ} 58^{\prime} 48^{\prime \prime} \mathrm{E}$, Norikura_2 36 $12^{\prime} 19^{\prime \prime} \mathrm{N}$ $137^{\circ} 57^{\prime} 98^{\prime \prime E}$; morph II, Sanjiro $36^{\circ} 21^{\prime} 24^{\prime \prime} \mathrm{N} 138^{\circ} 08^{\prime} 78^{\prime \prime} \mathrm{E}$, Hinokizawa $36^{\circ} 20^{\prime} 35^{\prime \prime} \mathrm{N}$ $138^{\circ} 09^{\prime} 18^{\prime \prime} \mathrm{E}$; morph III, Hora $36^{\circ} 28^{\prime} 03^{\prime \prime} \mathrm{N} 137^{\circ} 98^{\prime} 47^{\prime \prime} \mathrm{E}$, Misuzu $36^{\circ} 26^{\prime} 32^{\prime \prime} \mathrm{N}$ $\left.138^{\circ} 01^{\prime} 26^{\prime \prime E}\right)$. Population genetic analysis and tests for deviation from Hardy-Weinberg equilibrium (HWE) were performed with FSTAT version 2.9.3 software [10]. Genetic structure was analyzed after Bayesian clustering with STRUCTURE 2.1.3 software by assuming an admixture model and correlated allele frequencies [11] [12]. The simulated $K$ value ranged from 1 to 10 . Ten runs were conducted for each $K$ value, and $\Delta K$ was calculated from the mean log likelihood LnP (D) value of each $K$. The simulations conducted with 1,000,000 burn-in iterations and 100,000 Markov chain Monte Carlo repetitions after burn-in.

\section{Results and Discussion}

A total of 3,922,364 reads identified as microsatellite loci were generated in a run of the Miseq genetic sequencer. The QDD pipeline analysis detected 4492 putative microsatellite loci. Among those, 96 primer pairs were tested. A total of seven primer pairs amplified microsatellite loci in all 93 individuals. In some populations, marker of cisi 8 was not amplified (Table 1).

The number of alleles per locus in morph I ranged from 1 to 7 (population means, 2.6 and 3.0), in morph II from 1 to 9 (population mean, 3.4 and 4.3), and in morph III from 1 to 10 (population means, 3.7 and 4.9) (Table 2). In morph I populations, the average observed heterozygosity $\left(H_{\mathrm{o}}\right)$ was 0.05 and 0.15 and the average expected heterozygosity $\left(H_{\mathrm{e}}\right)$ was 0.28 and 0.33 . In morph II populations, average $H_{\mathrm{o}}$ was 0.34 and 0.36 and average $\mathrm{H}_{\mathrm{e}}$ was 0.43 . In morph III populations, average $H_{\mathrm{o}}$ was 0.11 and 0.19 and average He was 0.36 and 0.49 (Table 2). The average $H_{\mathrm{e}}$ and $H_{\mathrm{o}}$ values thus indicated significant deviation from HWE $(p<0.01)$ in the morph I and III populations. 
Table 1. Characteristics of eight microsatellite loci in Cimicifuga simplex ${ }^{\dagger}$.

\begin{tabular}{|c|c|c|c|c|c|c|}
\hline Locus & & Primer sequences $\left(5^{\prime}-3^{\prime}\right)$ & $\begin{array}{l}\text { Repeat } \\
\text { motif }\end{array}$ & $\begin{array}{c}\text { Fluorescent } \\
\text { label }^{\ddagger}\end{array}$ & Size range (bp) & $\begin{array}{c}\text { GenBank accession } \\
\text { no. }\end{array}$ \\
\hline \multicolumn{7}{|c|}{ Multiplex 1} \\
\hline \multirow[b]{2}{*}{ Cisil } & F: & TTCCTATGAATCCAACGAGCA & \multirow[b]{2}{*}{ AAT } & \multirow[b]{2}{*}{ FAM } & \multirow[b]{2}{*}{$316-339$} & \multirow[b]{2}{*}{ LC279064 } \\
\hline & $\mathrm{R}:$ & GCGTTCGATTCAATATCCATATGGG & & & & \\
\hline \multirow{2}{*}{ Cisi2 } & $\mathrm{F}:$ & CGCGTTCGTTGTCTTGACAT & \multirow{2}{*}{ AG } & \multirow{2}{*}{ VIC } & \multirow{2}{*}{$147-209$} & \multirow{2}{*}{ LC279065 } \\
\hline & $\mathrm{R}:$ & GCGCACCCAATGATACAACG & & & & \\
\hline \multirow{2}{*}{ Cisi3 } & $\mathrm{F}:$ & GTTCCTAGGACAGGGCATCA & \multirow{2}{*}{ AT } & \multirow{2}{*}{ NED } & \multirow{2}{*}{$100-201$} & \multirow{2}{*}{ LC279066 } \\
\hline & $\mathrm{R}:$ & GGGACAAGCTCTAGGTATACCC & & & & \\
\hline \multirow[b]{2}{*}{ Cisi4 } & F: & ATCACAACCCAATCCCGTCC & \multirow[b]{2}{*}{ AG } & \multirow[b]{2}{*}{ PET } & \multirow[b]{2}{*}{$103-153$} & \multirow[b]{2}{*}{ LC279067 } \\
\hline & $\mathrm{R}:$ & AGGTTTCTTCGACAGTTGCT & & & & \\
\hline \multicolumn{7}{|c|}{ Multiplex 2} \\
\hline \multirow{2}{*}{ Cisi5 } & F: & TCCAATGAATCATACATGAAATGAGT & \multirow{2}{*}{ AAT } & \multirow{2}{*}{ FAM } & \multirow{2}{*}{$248-300$} & \multirow{2}{*}{ LC279068 } \\
\hline & $\mathrm{R}:$ & GTGACAGGTGTGGTCCGAAA & & & & \\
\hline \multirow{2}{*}{ Cisi6 } & F: & AGCAATTAGTAGTCAGCCGGG & \multirow{2}{*}{ AAG } & \multirow{2}{*}{ VIC } & \multirow{2}{*}{$202-211$} & \multirow{2}{*}{ LC279069 } \\
\hline & $\mathrm{R}:$ & GACCTCCAGACCATTCAGCA & & & & \\
\hline \multirow{2}{*}{ Cisi7 } & F: & TTCGATGCCAACCTGCTACA & \multirow{2}{*}{$\mathrm{AC}$} & \multirow{2}{*}{ NED } & \multirow{2}{*}{$106-233$} & I $C 270070$ \\
\hline & $\mathrm{R}:$ & ATCCATTATCCAAGCCTCAGG & & & & \\
\hline & F: & CCTGTAACATGGCTCCCATT & & & & \\
\hline Cisi8 & $\mathrm{R}:$ & GCAGGTACCACGGAGGATTTA & AT & PET & $246-377$ & LC279071 \\
\hline
\end{tabular}

${ }^{\dagger}$ Annealing temperature was $60^{\circ} \mathrm{C}$ for all loci. ' Sequence of fluorescent labels: FAM = 5'-GCCTCCCTCGCGCCA-3', VIC = 5'-GCCTTGCCAGCCCGC-3', $\mathrm{NED}=$ 5'-CAGGACCAGGCTACCGTG-3', PET = 5'-CGGAGAGCCGAGAGGTG-3'.

Bayesian clustering with STRUCTURE identified three C. simplex populations (Figure 1) consistent with the three recognized pollination morphs. This result indicates that the eight microsatellite markers are valid for identifying the three morphs of $C$. simplex. Further, a little gene flow from morph I to III was detected.

The eight microsatellite markers described in this study were successfully used to detect genetic variation within populations and genetically distinguish the three pollination morphs. Thus, they will be useful in conservation genetic studies of $C$. simplex. In addition, the finding that pollination morphs I and III have relatively low genetic diversity is useful information for future conservation planning for C. simplex.

\section{Acknowledgements}

We thank M. Konishi (Nakano), G. Kudo, and S. Ueda for technical support and helpful discussion, and S. Duhon for English editing. We thank the Chubu District Forest Office (Forestry Agency), the Chubu Regional Office for Nature Conservation (Ministry of the Environment), and the Matsumoto Regional 
Table 2. Results of primer screening for eight microsatellite loci in six population of $C i$ micifuga simplex.

\begin{tabular}{|c|c|c|c|c|c|c|}
\hline \multirow[b]{3}{*}{ Locus } & \multicolumn{6}{|c|}{ morph I } \\
\hline & \multicolumn{3}{|c|}{ Norikura_1 $(n=12)$} & \multicolumn{3}{|c|}{ Norikura_1 $(n=12)$} \\
\hline & $A$ & $\mathrm{He}$ & Ho & $A$ & $\mathrm{He}$ & Ho \\
\hline Cisi 1 & 1 & 0.000 & 0.000 & 1 & 0.000 & 0.000 \\
\hline Cisi 2 & 2 & 0.083 & 0.083 & 2 & 0.030 & 0.030 \\
\hline Cisi 3 & 7 & 0.879 & $0.286^{*}$ & 4 & 0.857 & $0.000^{*}$ \\
\hline Cisi 4 & 7 & 0.824 & 0.667 & 3 & 0.190 & $0.000^{*}$ \\
\hline Cisi 5 & 1 & 0.000 & 0.000 & 1 & 0.000 & 0.000 \\
\hline Cisi 6 & 1 & 0.000 & 0.000 & 1 & 0.000 & 0.000 \\
\hline Cisi 7 & 2 & 0.533 & $0.000^{*}$ & 6 & 0.879 & $0.286^{*}$ \\
\hline Cisi 8 & - & - & - & - & - & - \\
\hline \multirow[t]{3}{*}{ Average } & 3.0 & 0.33 & $0.15^{*}$ & 4.3 & 0.43 & $0.34^{*}$ \\
\hline & \multicolumn{6}{|c|}{ morph II } \\
\hline & \multicolumn{3}{|c|}{ Norikura_1 $(n=12)$} & \multicolumn{3}{|c|}{ Norikura_1 $(n=12)$} \\
\hline Locus & $A$ & $\mathrm{He}$ & Ho & $A$ & $\mathrm{He}$ & Ho \\
\hline Cisi 1 & 1 & 0.000 & 0.000 & 1 & 0.000 & 0.000 \\
\hline Cisi 2 & 2 & 0.091 & 0.091 & 3 & 0.342 & 0.375 \\
\hline Cisi 3 & 5 & 0.407 & 0.455 & 6 & 0.683 & 0.875 \\
\hline Cisi 4 & 3 & 0.621 & 0.333 & 2 & 0.527 & $0.000^{*}$ \\
\hline Cisi 5 & 4 & 0.333 & 0.273 & 1 & 0.000 & 0.000 \\
\hline Cisi 6 & 2 & 0.337 & 0.200 & 2 & 0.458 & 0.375 \\
\hline Cisi 7 & 9 & 0.856 & 0.778 & 7 & 0.835 & 0.857 \\
\hline Cisi 8 & 8 & 0.825 & 0.625 & 5 & 0.593 & 0.429 \\
\hline \multirow[t]{3}{*}{ Average } & 4.3 & 0.43 & 0.34 & 3.4 & 0.43 & 0.36 \\
\hline & \multicolumn{6}{|c|}{ morph III } \\
\hline & \multicolumn{3}{|c|}{ Norikura_1 $(n=12)$} & \multicolumn{3}{|c|}{ Norikura_1 $(n=12)$} \\
\hline Locus & $A$ & $\mathrm{He}$ & Ho & $A$ & $\mathrm{He}$ & Ho \\
\hline Cisi 1 & 1 & 0.000 & 0.000 & 1 & 0.000 & 0.000 \\
\hline Cisi 2 & 1 & 0.000 & 0.000 & 2 & 0.067 & 0.067 \\
\hline Cisi 3 & 6 & 0.711 & 0.800 & 5 & 0.660 & $0.222^{*}$ \\
\hline Cisi 4 & 8 & 0.895 & $0.111^{*}$ & 8 & 0.909 & $0.111^{*}$ \\
\hline Cisi 5 & 3 & 0.329 & $0.000^{*}$ & 3 & 0.543 & $0.000^{*}$ \\
\hline Cisi 6 & 1 & 0.000 & 0.000 & 1 & 0.000 & 0.000 \\
\hline Cisi 7 & 6 & 0.579 & 0.400 & 10 & 0.844 & $0.250^{*}$ \\
\hline Cisi 8 & - & - & - & 9 & 0.855 & $0.250^{*}$ \\
\hline Average & 3.7 & 0.36 & $0.19^{*}$ & 4.9 & 0.48 & $0.11^{\star}$ \\
\hline
\end{tabular}

Note: $A=$ number of alleles; $H \mathrm{e}=$ expected heterozygosity; $H \mathrm{o}=$ observed heterozygosity; $n=$ number of samples screened. ${ }^{\star}$ Significant deviation from Hardy-Weinberg equilibrium $(p<0.01)$. 


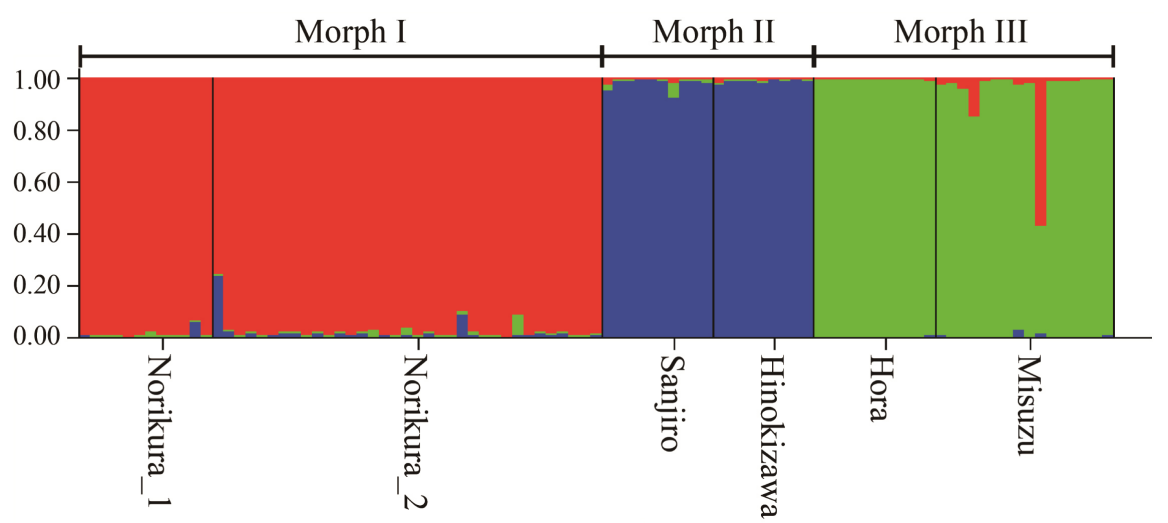

(a)

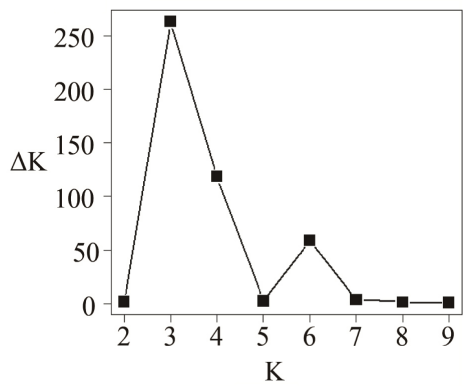

(b)

Figure 1. (a) STRUCTURE analysis results for eight microsatellite loci in six C. simplex populations. Each individual is represented by a vertical bar consisting of three colored segments representing the estimated fraction of the genome belonging to each cluster (b) Delta $K$ plot showing a peak at $K=3$ (best $K$ ).

Office (Nagano Prefectural Government) for permission to work in the area. This study was supported by the Japan Ministry of Education, Culture, Sports, Science and Technology (15H02641 to TI) and Nagano Society for the Promotion of Science (to TT).

\section{References}

[1] Nakai, T. (1916) Notulæ ad plantas Japoniæ et Koreæ XI. The Botanical Magazine, 30, 145-147. https://doi.org/10.15281/jplantres1887.30.140

[2] Emura, K.M. (1970) Cytotaxonomical Study on the Eurasiatic Species of the Genus Cimicifuga. 2. The Journal of Japanese Botany, 45, 362-377.

[3] Association of Wildlife Research and EnVision (2007) Search System of Japanese Red Data. http://jpnrdb.com/

[4] Koeda, M., Aoki, Y., Sakurai, N. and Nagai, M. (1995) Studies on the Chinese Crude Drug “Shoma." IX. Three Novel Cyclolanostanol Xylosides, Cimicifugosides H-1, H-2 and H-5, from Cimicifuga rhizome. Chemical and Pharmaceutical Bulletin, 43, 771-776. https://doi.org/10.1248/cpb.43.771

[5] Pellmyr, O. (1986) Three Pollination Morphs in Cimicifuga simplex, Incipient Speciation Due to Inferiority in Competition. Oecologia, 68, 304-307.

[6] Kuzume, H. and Itino, T. (2013) Congruence between Pollination Morphs and Genotypes Based on Internal Transcribed Spacer (ITS) Sequences of Nuclear Ribosomal DNA in Cimicifuga simplex (Ranunculaceae). The Journal of Japanese Bota- 
$n y, 88,176-181$.

[7] Meglécz, E., Costedoat, C., Dubut, V., Gilles, A., Malausa, T., Pech, N. and Martin, J.F. (2010) QDD: A User-Friendly Program to select Microsatellite Markers and Design Primers from Large Sequencing Projects. Bioinformatics, 26, 403-404. https://doi.org/10.1093/bioinformatics/btp670

[8] Blacket, M.J., Robin, C., Good, R.T., Lee, S.F. and Miller, A.D. (2012) Universal Primers for Fluorescent Labelling of PCR Fragments-An Efficient and Cost Effective Approach to Genotyping by Fluorescence. Molecular Ecology Resources, 12, 456-463. https://doi.org/10.1111/j.1755-0998.2011.03104.x

[9] Brownstein, M.J., Carpten, J.D. and Smith, J.R. (1996) Modulation of Non-Templated Nucleotide Addition by Taq DNA polymerase: Primer Modifications That Facilitate Genotyping. Biotechniques, 20, 1004-1006.

[10] Goudet, J. (1995) FSTAT: A Computer Program to Calculate F-Statistics, Version 1.2. The Journal of Heredity, 86, 485-486. https://doi.org/10.1093/oxfordjournals.jhered.a111627

[11] Pritchard, J.K., Stephens, M. and Donnelly, P. (2000) Inference of Population Structure Using Multilocus Genotype Data. Genetics, 155, 945-959.

[12] Evanno, G., Regnaut, S. and Goudet, J. (2005) Detecting the Number of Clusters of Individuals Using the Software STRUCTURE: A Simulation Study. Molecular Ecology, 14, 2611-2620. https://doi.org/10.1111/j.1365-294X.2005.02553.x 